\title{
Efficient Combination of Taxes on Fuel and Vehicles
}

\author{
Geir H. M. Bjertnces*
}

\begin{abstract}
A tax on fuel combined with tax exemptions or subsidies for fuel-efficient vehicles is implemented in many countries to reduce greenhouse gas emissions and other negative externalities from road traffic. This study, however, shows that a tax on fuel should be combined with heavier taxation of fuel-efficient vehicles to curb externalities from road traffic. The tax on fuel is implemented in order to curb externalities linked to both consumption of fuel and road use. A heavier tax on fuel-efficient vehicles prevent motorists from avoiding the road user charge on fuel by purchasing fuel-efficient vehicles.
\end{abstract}

Keywords: Transportation, Optimal taxation, Environmental taxation, Global warming

https://doi.org/10.5547/01956574.40.SI1.gbje

\section{INTRODUCTION}

Road transport is essential to maintain an efficient flow of goods, services and people, but generates costly negative externalities in the form of $\mathrm{CO} 2$ emissions, local air pollution, accidents, congestion and noise. Many countries have implemented taxes on fuel combined with tax exemptions or subsidies for fuel-efficient vehicles to curb externalities linked to both fuel and mileage. However, the gain in terms of reduced externalities per liter of fuel is diminished by the fact that households avoid the mileage-related tax component by purchasing more fuel-efficient vehicles, according to the highly influential study by Parry and Small (2005). Their optimal US and UK tax rates on gasoline are reduced accordingly. A range of other studies have adopted their method to calculate optimal tax rates on fuel in other countries; see e.g. Anton-Sarabia and Hernandez-Trillo (2014), Lin and Zeng (2014).

An alternative strategy consists of imposing a tax on fuel-efficient vehicles which cancels out the gains of this avoidance. This strategy has implications for the optimal fuel tax, as avoidance resulted in a lowering of the optimal tax rate on fuel in Parry and Small (2005). Their optimal tax rate on gasoline also includes a revenue-raising Ramsey tax component. However, according to Jacobs and de Mooij (2015) the Ramsey tax component is excluded from a welfare-maximizing tax system. Hence, more research is required to reveal how taxes on fuel and vehicles should be designed to curb externalities from road traffic.

The present study explores whether this alternative strategy is desirable. The study develops a new model framework which calculates optimal tax formulas for combinations of taxes on fuel and vehicles. The theoretical foundation for these tax formulas is based on pioneering contributions by Innes (1996) and Fullerton and West (2002). However, the results of these studies are difficult to transform into optimal real-world taxes on fuel and vehicles. Significant progress is made in the

* $\quad$ Statistics Norway, Research Department, P.O. BOX 8131 Dep, NO-0033 Oslo, Norway. E-mail: ghb@ssb.no.

The Energy Journal, Vol. 40, SI1. Copyright (C) 2019 by the IAEE. All rights reserved. 
present study, which develops these theories into operational tax formulas that are comparable with current taxation of fuel and vehicles. Scenarios with myopic behavior and electric vehicles (EVs) are included. The study shows that the tax rate on fuel in both the US and the UK is less than optimal, and that the tax on fuel-efficient vehicles should exceed the tax on fuel-intensive vehicles.

The rest of the paper is divided into four sections; Section 2 provides a literature review, Section 3 presents the model and Section 4 compares optimal taxes on fuel and vehicles with current taxes on fuel and vehicles. Section 5 provides a conclusion.

\section{LITERATURE REVIEW}

Parry and Small (2005) show that the optimal uniform tax rate on gasoline in the United States is more than twice the current rate, while that for the United Kingdom is about half the current rate. Their optimal tax rate on gasoline consists of an adjusted Pigouvian tax component which includes damage from carbon emissions and other driving-related externalities, a Ramsey tax component designed to raise tax revenue, and a congestion feedback component which captures welfare gains as labor supply increased as congestion decreases. Driving-related externalities due to congestion and accidents as well as the Ramsey tax component are dominant, while global warming and congestion feedback are modes. Anderson and Auffhammer (2014) estimate higher accident-related externalities, which suggests that the UK gasoline tax is closer to the optimal level than the US tax. Several objections can be made to the methodology in Parry and Small (2005), however. First, differentiated taxes on purchase of vehicles are as mentioned not considered, even though Innes (1996), Fullerton and West (2002, 2010) and De Borger (2001) show that restrictions on taxes on the use of vehicles imply that taxes on the purchase of vehicles are desirable. Indeed, subsidizing substitutes for polluting goods might be desirable when governments are unable to tax emissions directly, according to Sandmo (1976). Second, their optimal tax rate on gasoline includes a Ramsey tax component. However, according to Atkinson and Stiglitz (1976), a general set of assumptions excludes the Ramsey tax component from a welfare-maximizing tax system. Indeed, Jacobs and de Mooij (2015) show that a Pigouvian tax on polluting goods is part of a welfare-maximizing tax system within a Mirrlees-economy framework. Third, the tax theory adopted by Parry and Small (2005) is unable to generate a unique optimal tax rate on polluting goods according to Fullerton (1997). The explanation is that the allocation of resources is unchanged when a uniform tax increase on consumer goods is combined with a proportional, revenue-neutral reduction in taxation of income. Hence, welfare is unchanged even though the tax rate on polluting goods is increased.

Innes (1996) and Fullerton and West $(2002,2010)$ study the optimal design of taxes on both fuel and vehicles. Innes (1996) shows that optimal vehicle taxes, or their regulatory equivalents, approximately equal the social cost of a vehicle's predicted emissions less the portion of costs that is internalized by a uniform gasoline tax. Fullerton and West (2002) extend his analysis and explore tax combinations that implement the social planner choices of mileage, engine size, pollution control equipment, and fuel type. They find that vehicles with bigger engines should be subsidized (taxed) if the tax rate on fuel, which equals the marginal damage per gallon of fuel, more (less) than completely internalizes the impact of engine size. According to their study, empirical investigations are required to determine whether to tax or subsidize vehicles with large engines. Fullerton and West (2010) extend the analysis in Fullerton and West (2002) with vehicle age and simulate different scenarios. They find that the three-part instrument involving a gas tax, an engine-size subsidy, and a 
new-car subsidy maximize welfare. The engine-size subsidy does not increase welfare significantly, however.

These insightful studies leave several questions unanswered. First, Fullerton and West (2002) do not investigate how the optimal tax rate on fuel should be designed when households avoid the mileage-related component of fuel tax by purchasing more fuel-efficient vehicles. In contrast, the optimal tax rate on fuel in Parry and Small (2005) is reduced due to such avoidance. Second, the optimal engine-size subsidy is desirable if the tax on fuel is unable to completely internalize the impact of engine size. However, they are unable to determine the size or the sign of the subsidy. Hence, these results are hard to transform into optimal real-world taxes on fuel and vehicles. Third, several empirical studies find that households have rational expectations when purchasing vehicles; see Sallee et al. (2016) and Busse et al. (2013). Some studies find support for myopic behavior, however; see Grigolon et al. (2014) and Allcott and Wozny (2014). Myopic behavior is not considered by Innes (1996) or Fullerton and West (2002, 2010).

These weaknesses in Parry and Small (2005) concerning their omission of taxation of vehicles, their Ramsey tax component, and the lack of a unique tax rate, and issues in Fullerton and West $(2002,2010)$ concerning the lack of operational tax estimates, the impact of tax avoidance, and failure to consider myopic behavior are resolved in this study. The study contributes by developing a new model framework which calculates optimal combinations of taxes on fuel and vehicles which are comparable to real-world taxes. Tax estimates for scenarios with myopic behavior are included. Avoidance of mileage-related taxes on fuel through the purchase of fuel-efficient vehicles, and taxation of fuel-efficient vehicles to combat such avoidance, is incorporated into the model framework. The Ramsey tax component is excluded, as optimal taxes on fuel and vehicles are obtained by balancing the efficiency cost of tax distortions against the welfare gain of reduced externalities. The Pigouvian solution in Jacobs and de Mooij (2015) is not attainable, however, when policy instruments are restricted to a uniform tax on fuel and differentiated taxes on vehicles. The optimal tax difference between fuel and non-polluting goods includes optimal combinations of tax rates on fuel and non-polluting goods, and hence resolves the objection concerning the lack of a unique optimal tax rate. The optimal tax difference between fuel and non-polluting goods is compared with current tax differences in the US and the UK. The study also compares optimal and current taxes on vehicles in these countries.

\section{THE MODEL FRAMEWORK}

\subsection{Households}

Households choose driving distances and types of vehicle with varying fuel-efficiencies. Household $i$ 's utility, $u_{i}$, net of externalities is given by the quasilinear utility function

$$
u_{i}=u\left(k m_{i}\right)+b_{i}+c_{i}
$$

when a fuel-intensive vehicle is chosen. $b_{i}$ equals zero if a fuel-efficient vehicle is chosen. The utility, $u_{i}$, is determined by driving distance measured in kilometers, $k m_{i}$, consumption of a non-polluting consumer good, $c_{i}$, and the utility associated with owning a fuel-intensive vehicle instead of a fuel-efficient vehicle, $b_{i}$. The marginal utility of additional driving distance is positive, $u^{\prime}>0$, but declines as the driving distance increases, $u^{\prime \prime}<0$. This feature of the utility function illustrates the fact that some trips are more important/ necessary to households than other trips. The vehicle specific 
utility parameter, $b_{i}$, differs across households as transportation needs and requirements differ across households. Some households may prefer the fuel-efficient vehicle, i.e. their utility parameter, $b_{i}$, is negative. Household $i$ 's budget constraint is given by the equation

$$
c_{i}=y+k-\left(p_{l}+t_{l}\right) f_{j} k m_{i}-t_{c a r, j}-p_{c a r, j},
$$

where $j=h i g h$,low indicates fuel-intensive and fuel-efficient vehicle, respectively. Consumption of the non-polluting good, $c_{i}$, equals a fixed income, $y$, plus government transfers, $k$ minus costs of fuel, $\left(p_{l}+t_{l}\right) f_{j} k_{i}$, minus the tax on the chosen vehicle, $t_{c a r}, j$, minus the price of the chosen vehicle, $p_{c a r, j}$. Utility maximization with respect to $k m_{i}$ implies that

$$
\begin{aligned}
u_{k m_{i}}^{\prime} & =\left(p_{l}+t_{l}\right) f_{j}, \text { or } \\
k m_{i} & =d_{j}\left(t_{l}\right),
\end{aligned}
$$

where $j=$ high,low indicates the two types of vehicle. Equation (3) shows that the marginal gain in utility of one additional kilometer, $u_{k m_{i}}^{\prime}$, equals the private cost of driving one additional kilometer, $\left(p_{l}+t_{l}\right) f_{j}$. This cost is given by the price per liter of fuel, $p_{l}$, the tax per liter of fuel, $t_{l}$, and the fuel economy measured in liters per kilometer, $f_{j}$. Hence, driving is restricted to trips where the benefit exceeds the costs. Vehicle maintenance and capital depreciation are excluded from the operating costs of vehicles to simplify the model framework. However, a tax designed to correct for negative externalities is not influenced by these operating costs when externalities are not influenced by them.

The model framework is unable to distinguish between a tax on fuel-efficient vehicles and a subsidy on fuel-intensive vehicles. The tax on purchase of fuel-intensive vehicles, $t_{c a r}$, high, is therefore labeled $t_{c a r}$, and the tax on purchase of fuel-efficient vehicles is set equal to zero. The indirect utility function net of externalities for each household, $i$, for each type of vehicle, is found by inserting equation (2) into equation (1), and then implementing equation (4).

$$
\begin{aligned}
& v_{i, \text { high }}=u\left(d_{\text {high }}\left(t_{l}\right)\right)+b_{i}+y+k-\left(p_{l}+t_{l}\right) f_{\text {high }} d_{\text {high }}\left(t_{l}\right)-t_{\text {car }}-p_{\text {car }, \text { high }} \text {, and } \\
& v_{i, \text { low }}=u\left(d_{\text {low }}\left(t_{l}\right)\right)+y+k-\left(p_{l}+t_{l}\right) f_{\text {low }} d_{\text {low }}\left(t_{l}\right)-p_{\text {car }, \text { low }},
\end{aligned}
$$

Assume that households are ranked from high to low according to their utility parameter, $b_{i}$, and that the first $N$ households have chosen the fuel-intensive vehicle. Assume that their accumulated utility as a result of owning a fuel-intensive vehicle instead of a fuel-efficient vehicle, $B A$, is given by the expression

$$
B A=b_{\max } N-0,5 a N^{2},
$$

Where $a>0$ and no restrictions are imposed on $b_{\max }$. Households choose the type of vehicle that maximizes utility. Households therefore choose the fuel-intensive vehicle up to the point where household number $N$ is indifferent between types of vehicles. This equilibrium condition is given by the expression

$$
\begin{aligned}
& u\left(d_{\text {high }}\left(t_{l}\right)\right)+b_{\text {max }}-a N+y+k-\left(p_{l}+t_{l}\right) f_{\text {high }} d_{\text {high }}\left(t_{l}\right)-t_{\text {car }}-p_{\text {car }, \text { high }} \\
& =u\left(d_{\text {low }}\left(t_{l}\right)\right)+y+k-\left(p_{l}+t_{l}\right) f_{\text {low }} d_{\text {low }}\left(t_{l}\right)-p_{\text {car }, \text { low }} .
\end{aligned}
$$


Households that derive higher utility from owning a fuel-intensive vehicle will choose a fuel-intensive vehicle. Households that derive lower utility from owning a fuel-intensive vehicle will choose a fuel-efficient vehicle. Equation (7) determines the number of households which choose the fuel-intensive vehicle, as a function of fuel taxes, vehicle taxes, exogenous parameters and prices. Equation (7) is written as equation (8) to simplify notations.

$$
N=N\left(t_{l}, t_{c a r}\right)
$$

The total number of households is $\bar{N}$. Hence, the number of households that choose the fuel-efficient vehicle amounts to

$$
N_{\text {low }}=\bar{N}-N
$$

\subsection{Social costs}

The social cost of driving consists of damage from $\mathrm{CO} 2$ emissions and damage from mileage-related externalities. The damage from $\mathrm{CO} 2$ emissions, $S_{\mathrm{CO} 2}$, is given by the expression

$$
S_{\mathrm{CO} 2}=p_{\mathrm{CO} 2} N f_{\text {high }} d_{\text {high }}\left(t_{l}\right)+p_{\mathrm{CO} 2}(\bar{N}-N) f_{\text {low }} d_{\text {low }}\left(t_{l}\right) .
$$

The damage from $\mathrm{CO} 2$ emissions, $S_{\mathrm{CO} 2}$, equals the damage caused by $\mathrm{CO} 2$ emissions per liter of fuel, $p_{\mathrm{CO} 2}$, multiplied by the number of liters of fuel consumed by households with fuel-intensive vehicles, $N f_{\text {high }} d_{\text {high }}\left(t_{l}\right)$, plus the damage due to $\mathrm{CO} 2$ emissions per liter of fuel, $p_{\mathrm{CO} 2}$, multiplied by the number of liters of fuel consumed by households with fuel-efficient vehicles, $(\bar{N}-N) f_{\text {low }} d_{\text {low }}\left(t_{l}\right)$. A share of the current lifetime emissions from vehicles originates from production of vehicles and energy; see Hawkins et al. (2012). CO2 emissions from production of energy and vehicles are excluded from the model framework, however. This assumption is relevant when all polluters pay for their own emissions. The assumption is also relevant when these emissions are included in an emission trading system like that of the EU, and thus are neutralized by adjustments in other emission sources. The cost of mileage-related damage, $S_{d}$, is given by the expression

$$
S_{d}=p_{d} N d_{h i g h}\left(t_{l}\right)+p_{d}(\bar{N}-N) d_{l o w}\left(t_{l}\right)
$$

$S_{d}$ equals the damage per kilometer, $p_{d}$, multiplied by the number of kilometers driven by households with fuel-intensive vehicles, $N d_{\text {high }}\left(t_{l}\right)$, plus the damage per kilometer, $p_{d}$, multiplied by the number of kilometers driven by households with fuel-efficient vehicles, $(\bar{N}-N) d_{\text {low }}\left(t_{l}\right)$. The costs of traffic congestion and damage due to accidents dominates, while the costs of local pollution are more modest. These costs are influenced by a range of factors like drinking and driving, reckless driving and speeding. It is assumed that the present level of drinking and driving, reckless driving and speeding is preserved by current traffic laws and regulations.

\subsection{Taxation of fuel and vehicles}

Tax revenue collected is transferred to households. Each household receives a lump-sum transfer, $k$. The transfer is chosen to conform to the constraint of a balanced government budget. The government budget constraint is given by the following equation

$$
\bar{N} k=N t_{l} f_{\text {high }} d_{\text {high }}\left(t_{l}\right)+N t_{\text {car }}+(\bar{N}-N) t_{l} f_{\text {low }} d_{\text {low }}\left(t_{l}\right) .
$$


Total transfers, $\bar{N} k$, equal tax revenue from taxation of fuel for fuel-intensive vehicles, $N t_{l} f_{\text {high }} d_{\text {high }}\left(t_{l}\right)$, plus tax revenue from taxation of fuel-intensive vehicles, $N t_{\text {car }}$, plus tax revenue from taxation of fuel for fuel-efficient vehicles, $(\bar{N}-N) t_{l} f_{\text {low }} d_{\text {low }}\left(t_{l}\right)$.

The welfare function is given by the indirect utility function minus the social costs of road traffic. The sum of indirect utility functions net of externalities, equation (5), is found by accumulating over the number of individuals choosing fuel-efficient and fuel-intensive vehicles. The accumulated utility associated with owning a fuel-intensive vehicle is given by equation (6). The social costs of road traffic are given by equations (10) and (11). The government budget constraint, equation (12), and the condition determining the allocation of vehicles, equation (8), are incorporated in the welfare function. The government chooses the uniform tax rate on fuel, $t_{l}$, and the tax on purchase of fuel-intensive vehicles, $t_{c a r}$, to maximize welfare. The problem is

$$
\begin{aligned}
& \operatorname{Max}_{t_{l}, t_{\text {car }}} \bar{N} y+N\left(t_{l}, t_{\text {car }}\right) u\left(d_{\text {high }}\left(t_{l}\right)\right)+b_{\text {max }} N\left(t_{l}, t_{\text {car }}\right)-\frac{1}{2} a N\left(t_{l}, t_{\text {car }}\right)^{2} \\
& +\left(\bar{N}-N\left(t_{l}, t_{\text {car }}\right)\right) u\left(d_{\text {low }}\left(t_{l}\right)\right)-N\left(t_{l}, t_{\text {car }}\right)\left[p_{\text {car }, \text { high }}+p_{l} f_{\text {high }} d_{\text {high }}\left(t_{l}\right)\right] \\
& -\left(\bar{N}-N\left(t_{l}, t_{\text {car }}\right)\right)\left[p_{\text {car }, \text { low }}+p_{l} f_{\text {low }} d_{\text {low }}\left(t_{l}\right)\right]-p_{\text {CO2 }} N\left(t_{l}, t_{\text {car }}\right) f_{\text {high }} d_{\text {high }}\left(t_{l}\right) \\
& -p_{\text {CO2 }}\left(\bar{N}-N\left(t_{l}, t_{\text {car }}\right)\right) f_{\text {low }} d_{\text {low }}\left(t_{l}\right)-p_{d} N\left(t_{l}, t_{\text {car }}\right) d_{\text {high }}\left(t_{l}\right) \\
& -p_{d}\left(\bar{N}-N\left(t_{l}, t_{\text {car }}\right)\right) d_{\text {low }}\left(t_{l}\right) .
\end{aligned}
$$

The tax on fuel affects the number of fuel-intensive vehicles, $N\left(t_{l}, t_{c a r}\right)$, the driving distance of fuel-intensive vehicles, $d_{\text {high }}\left(t_{l}\right)$, and the driving distance of fuel-efficient vehicles, $d_{\text {low }}\left(t_{l}\right)$. The tax on purchase of fuel-intensive vehicles affects the number of fuel-intensive vehicles, $N\left(t_{l}, t_{c a r}\right)$. Note that choice of transfers, $k$, is excluded from the optimization problem as the government budget constraint is incorporated in the welfare function. The first order conditions imply that

$$
\begin{aligned}
& u\left(d_{\text {high }}\left(t_{l}\right)\right)+b_{\text {max }}-a N-p_{\text {car }, \text { high }}-p_{l} f_{\text {high }} d_{\text {high }}\left(t_{l}\right)-p_{\text {CO2 }} f_{\text {high }} d_{\text {high }}\left(t_{l}\right)-p_{d} d_{\text {high }}\left(t_{l}\right) \\
& =u\left(d_{\text {low }}\left(t_{l}\right)\right)-p_{\text {car }, \text { low }}-p_{l} f_{\text {low }} d_{\text {low }}\left(t_{l}\right)-p_{\text {CO2 } 2} f_{\text {low }} d_{\text {low }}\left(t_{l}\right)-p_{d} d_{\text {low }}\left(t_{l}\right) .
\end{aligned}
$$

See appendix A. Second order conditions are presented in Appendix B. Equation (14) shows that benefits minus the private and social costs of one additional fuel-intensive vehicle equal the benefits minus private and social costs of one additional fuel-efficient vehicle . The optimal additional tax rate on fuel equals

$$
t_{l}^{*}=p_{\mathrm{CO} 2}+\frac{\left(N d_{{\text {high } t_{l}}^{\prime}}+(\bar{N}-N) d_{\text {low } t_{l}}{ }^{\prime}\right) p_{d}}{N d_{\text {high } t_{l}}{ }^{\prime} f_{\text {high }}+(\bar{N}-N) d_{\text {low } t_{l}}^{\prime} f_{\text {low }}} .
$$

The optimal additional tax rate on fuel, $t_{l}^{*}$, equals $\mathrm{CO} 2$-related damage per liter of fuel, $p_{\mathrm{CO} 2}$, plus the road user charge on fuel, labeled $t_{d}$, given by the second term on the right-hand side of equation (15). This road user charge equals the reduction in mileage-related damage due to a marginal tax increase on fuel (the numerator), divided by the reduction in fuel consumption due to a marginal tax increase on fuel (the denominator). Thus the road user charge on fuel equals the reduction in mile- 


\section{Figure 1. The optimal additional tax rate on fuel}

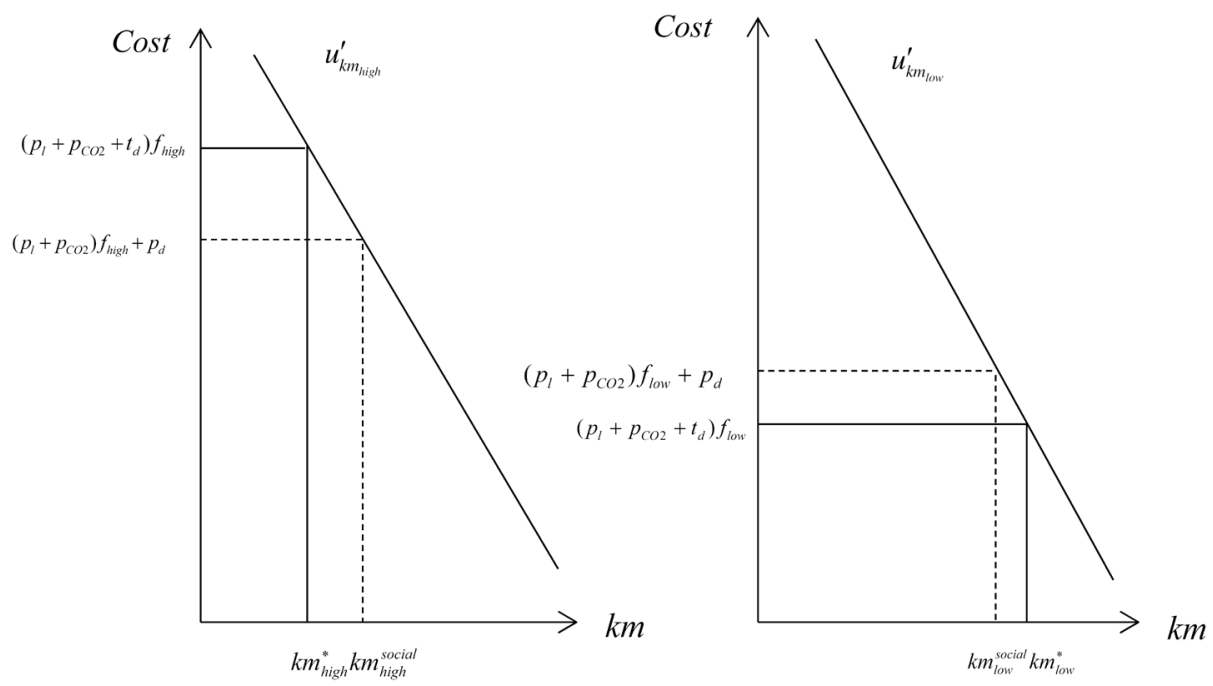

age-related damage per liter of reduced fuel consumption due to a marginal tax increase on fuel. The road user charge on fuel exceeds mileage-related externalities, $p_{d}$, for fuel-intensive vehicles. The road user charge on fuel is lower than mileage-related externalities, $p_{d}$, for fuel-efficient vehicles . The welfare-maximizing driving distance for fuel-intensive (fuel-efficient) vehicles is lower (higher) than the social planner solution $\mathrm{km}_{\text {high }}^{\text {social }}\left(\mathrm{km}_{\text {low }}^{\text {social }}\right)$ as policy tools are restricted. This outcome shows that the approach in Fullerton and West (2002), where the tax system is designed to implement the social planner solution, is inconsistent with the optimal tax solutions in the present study. A graphical illustration of the optimal additional tax rate based on equation (3) and (15), the social costs of driving, $\left(p_{l}+p_{\mathrm{CO} 2}\right) f_{j}+p_{d}$, and driving distance are presented in Figure 1 .

The welfare-maximizing tax on fuel-intensive vehicles equals

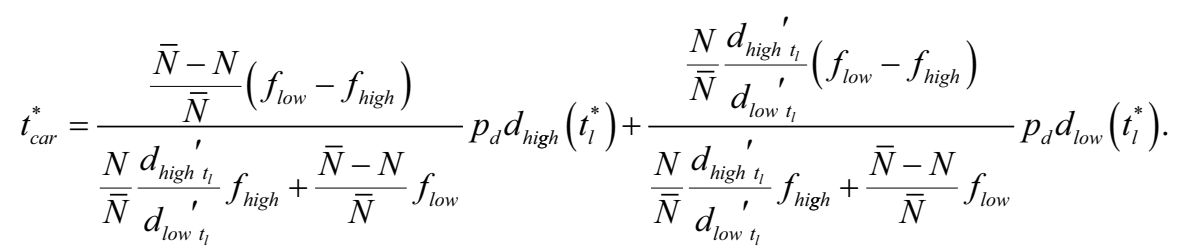

Both terms on the right side are negative. Hence, there should be heavier taxes on fuel-efficient vehicles than on fuel-intensive vehicles. Inserting the expression for the road user charge on fuel, $t_{d}$, from equation (15) into equation (16) implies that

$$
t_{\text {car }}^{*}=\left(p_{d}-t_{d} f_{\text {high }}\right) d_{\text {high }}\left(t_{l}\right)-\left(p_{d}-t_{d} f_{\text {low }}\right) d_{\text {low }}\left(t_{l}\right) .
$$

Equation (17) shows that the optimal tax on fuel-intensive vehicles, $t_{c a r}^{*}$, equals mileage-related damage minus road user charges for fuel-intensive vehicles, $\left(p_{d}-t_{d} f_{\text {high }}\right) d_{\text {high }}\left(t_{l}\right)$, minus the difference between mileage-related damage and road user charges for fuel-efficient vehicles, $\left(p_{d}-t_{d} f_{\text {low }}\right) d_{\text {low }}\left(t_{l}\right)$ . Future taxes on fuel are fully accounted for by households with rational expectations. Therefore, the $\mathrm{CO} 2$ tax on fuel provides a correct incentive for the choice of vehicle in this case. The choice of vehicle is distorted, however, as the mileage-related tax on fuel deviates from the mileage-related externality. The heavier tax on fuel-efficient vehicles neutralizes this distortion. Hence, household's 
Figure 2. The optimal allocation of vehicles

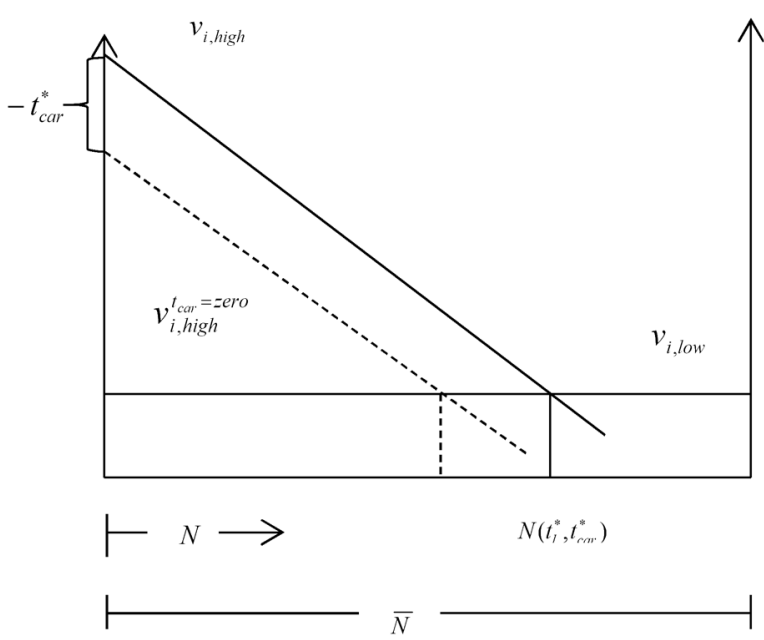

choice of vehicles implements the socially desirable allocation of vehicles given by equation (14). Solid lines in Figure 2 represent indirect utility, $v_{i, j}$, as a function of the allocation of vehicles when the optimal tax on fuel and vehicles is implemented. The dotted line represents the indirect utility, $v_{i, h i g h}^{t_{\text {car }}=\text { zero }}$, when the vehicle tax equals zero.

Some limitations should be considered when results are interpreted. The simple one-period model framework adopted, where households with specific preferences with respect to driving and type of vehicle choose driving distance and type of vehicle, suggests that results are limited to specific settings. The model framework excludes other choices, such as economical driving, and other externalities, like the rat race for status. Other policy tools designed to reduce traffic-related externalities, like parking fees, toll roads and CAFE standards, are omitted from the model framework. Heterogeneity along dimensions like demand for driving, income and environmental awareness are also excluded. The simple model framework is, however, able to arrive at optimal tax formulas that are mainly determined by the damage fuel and vehicles inflict upon society. Such damage is determined by empirical estimates, so tax formulas are mainly determined by these estimates.

\subsection{A fixed stock of vehicles}

This section assumes a fixed stock of vehicles, thereby precluding avoidance of road user charge on fuel through the purchase of fuel-efficient vehicles. The tax on purchase of vehicles does not influence driving distance in the current model framework. Thus the government maximization problem is reduced to choosing the tax rate on fuel. The problem is

$$
\begin{aligned}
& \operatorname{Max}_{t_{l}} \bar{N} y+N u\left(d_{\text {high }}\left(t_{l}\right)\right)+b_{\text {max }} N-\frac{1}{2} a N^{2} \\
& +(\bar{N}-N) u\left(d_{\text {low }}\left(t_{l}\right)\right)-N\left[p_{\text {car }, \text { high }}+p_{l} f_{\text {high }} d_{\text {high }}\left(t_{l}\right)\right] \\
& -(\bar{N}-N)\left[p_{\text {car }, \text { low }}+p_{l} f_{\text {low }} d_{\text {low }}\left(t_{l}\right)\right]-p_{\text {CO2 }} N f_{\text {high }} d_{\text {high }}\left(t_{l}\right) \\
& -p_{\text {CO2 }}(\bar{N}-N) f_{\text {low }} d_{\text {low }}\left(t_{l}\right)-p_{d} N d_{\text {high }}\left(t_{l}\right) \\
& -p_{d}(\bar{N}-N) d_{\text {low }}\left(t_{l}\right) .
\end{aligned}
$$


The first order condition is identical with the first order condition that determines $t_{l}$ in appendix A. The second order condition is presented in appendix C.

$$
t_{l}^{* *}=p_{\mathrm{CO} 2}+\frac{\left(N d_{{\text {high } t_{l}}^{\prime}}+(\bar{N}-N) d_{\text {low } t_{l}}^{\prime}\right) p_{d}}{N d_{\text {high } t_{l}}^{\prime} f_{\text {high }}+(\bar{N}-N) d_{\text {low } t_{l}}^{\prime} f_{\text {low }}} .
$$

The optimal tax formula for fuel, equation (19), is identical with the expression for the optimal tax formula for fuel in the case where households choose vehicles, equation (15). This shows that it is sub-optimal to lower the tax on fuel when households avoid the road user charge on fuel by purchasing fuel-efficient vehicles.

\subsection{Myopic behavior}

Empirical estimates by Allcott and Wozny (2014) show that vehicle prices move as though consumers are indifferent between 1 dollar in discounted future gas costs and 0.76 dollar in vehicle purchase price. Such myopic behavior is incorporated into the model framework in the present study by assuming that households value future discounted costs and gains of driving at 70 percent of actual value when choosing a vehicle. This feature is implemented by modifying the equilibrium condition, equation (7), where a household is indifferent between fuel-intensive and fuel-efficient vehicles. The new equilibrium condition is given by

$$
\begin{aligned}
& 0,7 u\left(d_{\text {high }}\left(t_{l}\right)\right)+b_{\text {max }}-a N+y+k-0,7\left(p_{l}+t_{l}\right) f_{\text {high }} d_{\text {high }}\left(t_{l}\right)-t_{\text {car }}-p_{\text {car }, \text { high }} \\
& =0,7 u\left(d_{\text {low }}\left(t_{l}\right)\right)+y+k-0,7\left(p_{l}+t_{l}\right) f_{\text {low }} d_{\text {low }}\left(t_{l}\right)-p_{\text {car }, \text { low }} .
\end{aligned}
$$

The allocation of vehicles is affected by myopic behavior, as future benefits of fuel-efficient vehicles are not fully taken into consideration when vehicles are purchased. The choice of driving distance is not affected because the utility and operating costs of driving take place in the same periods. The perfect-foresight government maximizes an individualistic welfare function in which actual future gains and costs are incorporated. The maximization problem of the government is found by replacing equation (7) with equation (20) in problem (13). First order conditions which determine the tax on fuel are identical with conditions in problem (13).

$$
t_{l}^{* * *}=p_{\mathrm{CO} 2}+\frac{\left(N d_{{\text {high } t_{l}}^{\prime}}^{\prime}+(\bar{N}-N) d_{\text {low } t_{l}}^{\prime}\right) p_{d}}{N d_{\text {high } t_{l}}^{\prime} f_{\text {high }}+(\bar{N}-N) d_{\text {low } t_{l}}^{\prime} f_{\text {low }}^{\prime}}
$$

The optimal tax formula for fuel should therefore not be modified on account of myopic behavior. First order conditions also imply that equation (14) is satisfied. However, the optimal purchase tax on fuel-intensive vehicles is modified according to equation (20); see appendix D.

$$
\begin{gathered}
t_{\text {car }}^{* * * *}=\frac{\frac{\bar{N}-N}{\bar{N}}\left(f_{\text {low }}-f_{\text {high }}\right)}{\frac{N}{\bar{N}} \frac{d_{\text {high } t_{l}}^{\prime}}{d_{\text {low } t_{l}}} f_{\text {high }}+\frac{\bar{N}-N}{\bar{N}} f_{\text {low }}} p_{d} d_{\text {high }}\left(t_{l}^{* * *}\right)+\frac{\frac{N}{\bar{N}} \frac{d_{\text {high } t_{l}}^{\prime}}{d_{\text {low } t_{l}}^{\prime}}\left(f_{\text {low }}-f_{\text {high }}\right)}{\frac{N}{\bar{N}} \frac{d_{\text {high } t_{l}}^{\prime}}{d_{\text {low } t_{l}}^{\prime}} f_{\text {high }}+\frac{\bar{N}-N}{\bar{N}} f_{\text {low }}} p_{d} d_{\text {low }}\left(t_{l}^{* * * *}\right) . \\
+0,3\left[u\left(d_{\text {low }}\left(t_{l}^{* * *}\right)\right)-\left(p_{l}+t_{l}^{* * * *}\right) f_{\text {low }} d_{\text {low }}\left(t_{l}^{* * *}\right)-\left(u\left(d_{\text {high }}\left(t_{l}^{* * *}\right)\right)-\left(p_{l}+t_{l}^{* * *}\right) f_{\text {high }} d_{\text {high }}\left(t_{l}^{* * *}\right)\right)\right]
\end{gathered}
$$


The first two terms on the right-hand side are both negative, and identical with the terms in equation (16). The last term is positive. The explanation is that households underestimate the rewards of a fuel-efficient vehicle. An additional purchase tax on vehicles with higher fuel consumption contributes to correcting for mistakes due to myopic behavior.

\subsection{Electric vehicles}

A user charge on electric vehicles is desirable to correct for mileage-related externalities. However, this section analyzes optimal taxation of fuel and purchases of electric vehicles when the use of electric vehicles is not taxed. The problem is analyzed within the present model framework by replacing low-emission vehicles with electric vehicles, and by assuming that the private cost of using an electric vehicle is zero. Thus, the driving distance for electric vehicles is determined by the condition, $u_{k m_{\text {low }}}^{\prime}=0$. CO2 emissions from production of electricity and electric vehicles are excluded. The maximization problem of the government is found by inserting $f_{\text {low }}=0$, and by assuming that $d_{\text {low }}\left(t_{l}\right)$ is fixed in the perfect foresight problem in (13). First order conditions imply that

$$
u_{k m_{\text {high }}}^{\prime}=p_{l} f_{\text {high }}+p_{\mathrm{CO} 2} f_{\text {high }}+p_{d} .
$$

Inserting equation (23) into equation (3) gives

$$
t_{l}^{* * * *}=p_{\mathrm{CO} 2}+\frac{p_{d}}{f_{\text {high }}} .
$$

Thus, the optimal tax difference between fuel and non-polluting consumer goods equals the marginal damage of $\mathrm{CO} 2$ emissions plus the mileage-related marginal damage of road transport. The first order condition with respect to $t_{c a r}$ combined with equations (24) and (7) implies that

$$
t_{\text {car }}^{* * *}=-p_{d} k m_{l o w} .
$$

Equation (25) shows that the optimal additional tax on purchase of electric vehicles equals mileage-related damage associated with electric vehicles. The cost of $\mathrm{CO} 2$ emissions and mileage-related damage due to fossil fuel vehicles is incorporated into the price of fuel. The cost of mileage-related damage due to electric vehicles is incorporated into the price of the vehicle. Thus, rational households face costs attributable to externalities when choosing between a fossil fuel vehicle and an electric vehicle. Note that greater damage from $\mathrm{CO} 2$ emissions, preferences for vehicles due to factors such as range anxiety, and price differences between vehicles do not alter the optimal additional tax on EVs expressed by equation (25). ${ }^{1}$

\subsection{Other tax instruments}

The impact of introducing other policy instruments is analyzed by calculating the social planner solution and then determining which policy packages implement the social planner solution. The social planner solution is found by maximizing the objective function in problem (13) with respect to the allocation of vehicles, $N$, and driving distance for each vehicle, $k m_{\text {high }}$ and $k m_{\text {low }}$. The first order conditions w.r.t $N$ imply that

1. Differences in mileage-related costs across geographic regions call for geographic tax differentiation across regions. Implementation of geographic tax differentiation favors an annual vehicle tax, as differentiated taxes on purchases are more likely to be subject to evasion. 


$$
\begin{aligned}
& u\left(k m_{\text {high }}\right)+b_{\text {max }}-a N-p_{\text {car }, \text { high }}-p_{l} f_{\text {high }} k m_{\text {high }}-p_{\text {CO2 }} f_{\text {high }} k m_{\text {high }}-p_{d} k m_{\text {high }} \\
& =u\left(k m_{\text {low }}\right)-p_{\text {car }, \text { low }}-p_{l} f_{\text {low }} k m_{\text {low }}-p_{\text {CO2 } 2} f_{\text {low }} k m_{\text {low }}-p_{d} k m_{\text {low }} .
\end{aligned}
$$

Equation (26) shows that the benefits minus private and social costs of one additional fuel-intensive vehicle equal the benefits minus private and social costs of one additional fuel-efficient vehicle. The first order conditions also imply that

$$
\begin{aligned}
& u_{k m_{\text {high }}}^{\prime}=p_{l} f_{\text {high }}+p_{\mathrm{CO} 2} f_{\text {high }}+p_{d}, \text { and } \\
& u_{k m_{\text {low }}}^{\prime}=p_{l} f_{\text {low }}+p_{\text {CO2 } 2} f_{\text {low }}+p_{d} .
\end{aligned}
$$

The left-hand sides of equations (27) and (28) equal the utility of one additional kilometer for each type of vehicle. This equals the price of fuel multiplied by fuel consumption per kilometer, plus the cost of carbon multiplied by fuel consumption per kilometer, plus the mileage-related damage caused by driving one kilometer.

The government is able to implement the social planner solution when the tax on fuel can be differentiated between vehicles with different fuel economies. Assuming rational expectations implies that the social planner solution is implemented by choosing a zero tax on fuel-intensive vehicles combined with tax rates on fuel which equals

$$
t_{l, j}=p_{C O 2}+\frac{p_{d}}{f_{j}}
$$

where $j=$ high,low. The proof consists of incorporating these tax rates into equations (3) and (7) and comparing with the social planner solution expressed by equations (26), (27) and (28). Note that the tax on fuel is higher for fuel-efficient vehicles in this case, so the result in Montage (2015) is confirmed. A tax on fuel which equals the marginal damage of $\mathrm{CO} 2$ emissions, a tax on driving distance which equals the marginal damage of mileage-related externalities, and a zero tax on fuel-intensive vehicles, also implements the social planner solution. ${ }^{2}$ Both these solutions lead to a more efficient allocation of vehicles and driving distance than the solution with a uniform tax on fuel combined with taxation of fuel-intensive vehicles; see also Ashley et al. (2017) and Montag (2015). However, a GPS-based system is more costly to administer and is likely to impose information-processing costs and undesirable surveillance; see Parry et al. (2007). A tax on fuel which differentiates between various characteristics of vehicles does not differentiate between geographic locations or peak and off-peak periods, and may lead to costly monitoring to prevent high-tax fuel vehicles using low-tax fuel.

One may argue that a road user charge based on odometer readings or pay-as-you-drive insurance combined with congestion charges and toll roads resembles GPS-based road user charges. However, such charges are costly to administer, susceptible to evasion, and lead to undesirable traffic planning designed to avoid toll stations; see Parry (2002). Parking fees, reduced speed-limits and road-investment strategies are also designed to curb traffic-related externalities. The optimal design of such policy tool combinations is beyond the scope of this study, however. 


\section{OPTIMAL VERSUS CURRENT TAXATION OF FUEL AND VEHICLES}

A few countries have introduced GPS-based road user charges on heavy duty vehicles, but systems for light duty passenger vehicles are lagging behind. However, many countries tax both fuel and vehicles to curb externalities from road traffic. This section illustrates results by comparing optimal combinations of taxes on fuel and vehicles with current taxes in the US and the UK. ${ }^{3}$

\subsection{Fuel}

The tax rate on fuel differs substantially across countries. The average US tax on gasoline amounted to 45.7 cents per gallon in 2017 according to the US Energy Information Administration. The average combined sales tax (8.4 percent according to Thomson Reuters, 2015) of spending the cost of one gallon of gasoline on non-polluting goods amounts to approximately 17.8 cents. Thus the current tax difference between fuel and non-polluting goods amounts to approximately 28 cents per gallon of gasoline in the US. The average toll per gallon of gasoline amounts to approximately 9 cents according to Bjertnæs (2017). The current US tax difference between fuel and non-polluting goods, including fees for toll roads, equals 0.37 dollar per gallon of gasoline. The tax difference between gasoline and non-polluting consumer goods in the UK amounts to the fuel tax of $£ 0.5795$ per liter of gasoline, or \$2.69 per gallon; see UK (2017). The additional value-added tax is levied on most goods including fuel, and thus does not influence the tax difference. Toll per gallon of gasoline on roads and bridges in the UK is marginal according to Bjertnæs (2017).

The formula for the optimal tax difference between fuel and non-polluting goods is given by equations (15), (19) and (21). Several simplifying assumptions are adopted in order to calculate the optimal tax difference. First, the utility function is formulated so that the reduction in mileage due to a tax increase on fuel is identical for households with a fuel-intensive and a fuel-efficient vehicle in the optimal solution, i.e. $d_{\text {high } t_{l}}{ }^{\prime}=d_{\text {low } t_{i}}{ }^{\prime}$. Second, parameters are chosen so that the stock of fuel-intensive and fuel-efficient vehicles is identical. Equation (15) is transformed into

$$
t_{l}^{*}=p_{C O 2}+\frac{p_{d}}{0,5 f_{\text {high }}+0,5 f_{\text {low }}} .
$$

The optimal tax difference between fuel and non-polluting goods equals the marginal damage of $\mathrm{CO} 2$ emissions plus the average mileage-related marginal damage in this case. The marginal damage of $\mathrm{CO} 2$ emissions, or social cost of carbon, has been estimated by more than 100 peer-reviewed studies according to the report from the Intergovernmental Panel on Climate Change (IPCC) (2007). The average cost estimate is $\$ 43$ per ton of $\mathrm{CO} 2$. A cost estimate of $\$ 50$ is common, as some recent estimates are higher. Consumption of one liter of gasoline generates $2.32 \mathrm{~kg} \mathrm{CO}$, which amounts to approximately $\$ 0.44$ per gallon of gasoline; see Table 1 . This estimate is relevant for countries facing a quota price, and for countries concerned with the global damage of carbon emissions.

The average mileage-related marginal damage related to road transport for the US and the UK amounts to \$1.92 and \$2.92 per gallon of gasoline, respectively, according to Parry and Small (2005). Hence, optimal taxes in the US and the UK amount to \$2.36 and \$3.36 per gallon, respectively, of gasoline. Anderson and Auffhammer (2014) show that accident-related externalities are related to the weight of vehicles. Internalizing such externalities by a weight-varying mileage tax or

3. The US and the UK are used as examples to enable a comparison with the results of Parry and Small (2005). The case of Germany and Norway is included in an earlier version of this study, see Bjertnæs (2017). 
Table 1: Tax rates and costs: USD per gallon of gasoline, 2016.

\begin{tabular}{|c|c|c|c|c|c|c|}
\hline & $\begin{array}{l}\text { The cost } \\
\text { of CO2 } \\
\text { emissions }\end{array}$ & $\begin{array}{l}\text { Average } \\
\text { mileage- } \\
\text { related costs }\end{array}$ & $\begin{array}{l}\text { Optimal tax } \\
\text { difference, } \\
\text { fuel vs. goods }\end{array}$ & $\begin{array}{l}\text { Current tax } \\
\text { difference, } \\
\text { fuel vs. goods }\end{array}$ & $\begin{array}{c}\text { Current fees, } \\
\text { toll road }\end{array}$ & $\begin{array}{l}\text { Current road } \\
\text { user charge, } \\
\text { tax plus fees }\end{array}$ \\
\hline USA & 0.44 & 1.92 & 2.36 & 0.28 & 0.09 & 0.37 \\
\hline UK & 0.44 & 2.92 & 3.36 & 2.69 & 0 & 2.69 \\
\hline
\end{tabular}

a $\$ 0.97-\$ 2.17$ per gallon of gasoline tax is similar for most vehicles. Their estimates suggest that the UK gas tax is closer to the optimal level than the US tax.

\subsection{Vehicles}

Several European countries redesigned their vehicle tax system in the mid-2000s and implemented bonus-malus schemes that favored fuel-efficient vehicles. Some countries imposed a $\mathrm{CO} 2$-based tax on purchase of vehicles, while other countries imposed annual CO2-based registration taxes; see Klier and Linn (2015). According to their study, CO2-based tax on purchase of vehicles leads to larger reductions in the average emission rates of new vehicles. The emission reduction of such taxation is eroded as sales of new vehicles expand, however (Alberini and Bareit, 2017), and as the retirement of high-emitting vehicles is postponed (Alberini et al., 2018). The annual CO2-based registration tax, levied on both new and existing vehicles, is not burdened by these undesirable impacts according to Alberini et al. (2018). The impact of these annual taxes on the average emission rates of new vehicles is modest, however, (Klier and Linn, 2015), and the cost per ton of reduced CO2 emissions is substantial (Alberini and Bareit, 2017).

The current annual UK vehicle excise duty increases with theoretical CO2 emissions per kilometer; see Brand et al. (2013). The tax is higher the first year after registration, and thus represents a mix between an annual tax and a tax on purchase of vehicles. The current US tax on vehicle purchases differs across states and counties. These taxes and fees generate a marginal tax difference between fuel-intensive and fuel-efficient vehicles. However, Goldberg (1998) argues that the US Corporate Average Fuel Economy (CAFE) standard acts as a modest firm-specific tax on fuel-intensive vehicles relative to fuel-efficient vehicles.

The optimal tax difference between fuel-intensive and fuel-efficient vehicles in the case with rational expectations is given by equation (16). This equation is employed to illustrate optimal US tax differences between the following Volkswagen Passat 2017 models: the 1.6 TDI, the 2.0 TDI DSG 4MOTION and the GTE plug-in hybrid. Tests show that their fuel consumption per kilometer equals $0.041,0.051$, and 0.041 liters, respectively. Parameter values presented in appendix E imply that the optimal tax on the 1.6 model is $\$ 1242$ more than on the 2.0 model. The optimal additional tax on the GTE also amounts to $\$ 1242$.

The optimal tax difference between fuel-intensive and fuel-efficient vehicles in the case with myopic behavior is given by equation (22). The optimal tax difference equals the optimal tax difference with rational expectations, equation (16), plus 30 percent of the difference between the utility minus the costs of driving a fuel-intensive vehicle, and the utility minus the costs of driving a fuel-efficient vehicle. The optimal tax on the 1.6 model is $\$ 417$ more than the 2.0 model in this case; see appendix E. The optimal additional tax on the GTE also equals $\$ 417$. A sensitivity test shows that the optimal additional tax, equation (22), equals zero when households value future discounted gains and costs at approximately 55 percent of actual values. However, empirical studies reveal more modest myopic behavior. 


\subsection{Electric vehicles}

The US federal tax credit per new electric vehicle ranges from \$2 500 to $\$ 7500$ according to the US department of energy. Many states offer additional benefits, including subsidies for charging stations. California, for example, offers an additional \$7 000 cash rebate for low income households that purchase an electric vehicle. However, some US states have imposed annual road user charges of \$50-300 as EV users avoid the user charge levied on fuel. EV owners do not pay vehicle taxes in the UK. A $£ 4000$ subsidy on the purchase of electric cars with a range greater than a specified limit has also been introduced, according to the UK government web site.

The optimal additional tax on electric vehicles is given by equation (25) when the use of electric vehicles is untaxed and households are rational. A lifetime driving distance of 240000 kilometer and mileage-related damage of $\$ 0.03$ per kilometer implies an optimal additional tax on electric vehicles of \$7 200. The optimal tax difference between fossil fuel vehicles and electric vehicles in the case with myopic behavior equals the optimal tax difference with rational expectations plus a correction for myopic behavior. The correction equals approximately thirty percent of a vehicle's lifetime fuel costs within the current model framework. The lifetime cost of fuel equals the optimal consumer price of fuel, $\$ 1.123$ per liter, multiplied by liters consumed per kilometer, 0.06 , multiplied by lifetime driving distance, $240000 \mathrm{~km}$. Thus, these assumptions generate an optimal additional tax on electric vehicles of approximately USD 2400 in this case.

\subsection{Policy implications}

The comparison of optimal and current taxation of fuel and vehicles in the present study reveals substantial differences. Both the optimal US tax difference between gasoline and non-polluting goods of \$2.36 per gallon, and the optimal UK tax difference of $\$ 3.36$ per gallon, are substantially higher than current tax differences. The corresponding optimal tax estimates in Parry and Small (2005) are only $\$ 1.01$ and $\$ 1.34$ per gallon of gasoline. The study also shows that the optimal tax on fuel should be combined with tax rebates for fuel-intensive vehicles. In contrast, many European countries have done quite the opposite, and implemented bonus-malus schemes with tax rebates for fuel-efficient vehicles. The US CAFE standard offers similar rebates for fuel-efficient vehicles.

The suggested tax increase on fuel may, however, face political resistance in countries like the US, where there is a low tax on fuel combined with high fuel consumption per capita; see Hammar et al. (2004). Opposing voters and lobby groups, on the other hand, are likely to benefit from the suggested optimal and lenient taxation of fuel-intensive vehicles. The optimal policy package, combining a tax increase on fuel with tax rebates on fuel-intensive vehicles, should therefore face less political resistance. The political restraints described in Hammar et al. (2004) indicate that substantial political resistance should be expected, however.

Many countries, including the US and the UK, have introduced tax exemptions and subsidies for electric vehicles to promote the development of clean transport technology, and possibly to prepare their car industry for an electric future. The present study shows that the optimal additional tax on electric vehicles equals the value of their mileage-related externalities when the use of EVs is untaxed and other market imperfections are absent. This optimal additional tax is reduced if sales of new EVs boost technological development. These mileage-related externalities are spread across the globe, and may therefore be substantial. It is challenging to quantify the externality per EV sold, but additional adverse impacts, such as increased car use and less public transport, should be expected; see Holtsmark and Skonhoft (2014) and Aasness and Odeck (2015). Externalities associated with 
a network of charging stations could justify tax exemptions for the purchase of EVs; see Greaker and Midttømme (2016). Shanjun et al. (2017) find, however, that direct subsidies for investing in charging stations are more efficient than subsidies for EVs. The expansion of EVs may also create a need for road user charges that are not based on fuel. The present study shows that the optimal tax on EVs equals the tax on fossil fuel vehicles when the road user charge is based on GPS tracking and other market imperfections are absent.

\section{CONCLUSION}

Many countries have implemented taxes on fuel combined with tax exemptions or subsidies for the purchase of fuel-efficient vehicles in order to curb externalities linked to both fuel and mileage. According to Parry and Small (2005), the gain in terms of reduced externalities per liter of fuel is diminished, however, as households avoid the mileage-related tax component by purchasing more fuel-efficient vehicles. Parry and Small's optimal tax rate on gasoline is reduced accordingly. The resulting optimal tax rate in the United States is more than twice as large as the current rate, while that for the United Kingdom is about half its current rate.

This study shows that such avoidance should be neutralized by heavier taxation of fuel-efficient vehicles, and that current taxation of fuel is sub-optimal in both the US and the UK. The theoretical foundation for this result is based on contributions by Innes (1996) and Fullerton and West (2002). The present study contributes by constructing operational tax formulas which show that the tax on fuel-efficient vehicles should exceed the tax on fuel-intensive vehicles. The study also contributes by showing that this result holds in cases with myopic households. Many countries, by contrast, have introduced tax exemptions or subsidies for fuel-efficient vehicles.

Several car manufacturers have recently been caught manipulating tests to classify their vehicles as fuel-efficient. Taxes are avoided and customers are cheated. The heavier tax on fuel-efficient vehicles lowers incentives for such avoidance, and hence contributes to solving this problem. Improved testing is of course an alternative.

\section{ACKNOWLEDGMENTS}

I am highly grateful for valuable comments from three anonymous referees, Stephen Smith, Vidar Christiansen, Mads Greaker, Andrea Schneider, attendees at the 39th Annual Meeting of the Norwegian Association of Economists, attendees at the OFS workshop on indirect taxes 2017, attendees at the 10th Norwegian-German Seminar on Public Sector Economics as well as attendees of seminars at Statistics Norway and the Norwegian Ministry of Finance.

\section{REFERENCES}

Aasness, Marie A. and James Odeck (2015). "The increase of electric vehicle usage in Norway- incentives and adverse effects." Eur. Transp. Res. Rev. 7(34). https://doi.org/10.1007/s12544-015-0182-4.

Alberini, A. and M. Bareit (2017). "The effects of registration taxes on new car sales and emissions: Evidence from Switzerland." Resource and Energy Economics, https://doi.org/10.1016/j.reseneeco.2017.03.005.

Alberini, A., M. Bareit, and M. Filippini (2018). "The impact of emissions-based taxes on the retirement of used and inefficient vehicles: The case of Switzerland." Journal of Environmental Economics and Management 88: 234-258. https://doi. org/10.1016/j.jeem.2017.12.004.

Allcott, H. and N. Wozny (2014). "Gasoline prices, fuel economy, and the energy paradox." The Review of Economics and Statistics XCVI(5). https://doi.org/10.1162/REST_a_00419. 
Anderson, M.L. and M. Auffhammer (2014). "Pounds That Kill: The External Costs of Vehicle Weight." Review of Economic Studies 81: 535-571. https://doi.org/10.1093/restud/rdt035.

Anton-Sarabia, A. and F. Hernandez-Trillo (2014). "Optimal gasoline tax in developing, oil-producing countries: The case of Mexico.” Energy Policy 67: 564-571. https://doi.org/10.1016/j.enpol.2013.11.058.

Ashley, L., M. Wikram, and W. Clifford (2017). "From gallons to miles: A disaggregated analysis of automobile travel and externality taxes.” Journal of public Economics 152: 34-46. https://doi.org/10.1016/j.jpubeco.2017.05.003.

Atkinson, A.B., and J.E. Stiglitz (1976). “The Design of Tax Structure: Direct versus Indirect Taxation.” Journal of Public Economics 6: 55-75. https://doi.org/10.1016/0047-2727(76)90041-4.

Bjertnæs, G.H., M. Tsygankova, and T. Martinsen (2013). "Norwegian Climate Policy Reforms in the Presence of an International Quota Market.” Energy Economics 39: 147-158. https://doi.org/10.1016/j.eneco.2013.05.001.

Bjertnæs G.H.M. (2017). “The Efficient Combination of Taxes on Fuel and Vehicles.” CESifo Working Paper, no 67892017.

Brand, C., J. Anable, and M. Tran (2013). "Accelerating the transformation to a low carbon passenger transport system: The role of car purchase taxes, feebates, road taxes and scrappage incentives in the UK." Transportation Research Part A 49: 132-148. https://doi.org/10.1016/j.tra.2013.01.010.

Busse, M.R., C.R. Knittel, and F. Zettelmyer (2013). "Are Consumers Myopic? Evidence from New and Used Car Purchases.” American Economic Review 103(1): 220-256. https://doi.org/10.1257/aer.103.1.220.

De Borger, B. (2001). "Discrete choice models and optimal two-part tariffs in the presence of externalities: optimal taxation of cars.” Regional Science and Urban Economics 31: 471-504. https://doi.org/10.1016/S0166-0462(00)00078-8.

Diamond, P.A. (1973). "Consumption externalities and imperfect corrective pricing." The Bell Journal of Economics and Management Science 4(2). https://doi.org/10.2307/3003052.

Fullerton, D. (1997). "Environmental Levies and Distortionary Taxation: Comment." American Economic Review 87(1).

Fullerton, D., and S.E. West (2002). "Can Taxes on Cars and on Gasoline Mimic an Unavailable Tax on Emissions." Journal of Environmental Economics and Management 43. https://doi.org/10.1006/jeem.2000.1169.

Fullerton, D., and S.E. West (2010). "Tax and Subsidy Combinations for the Control of Car Pollution." The B.E. Journal of Economic Analysis \& Policy 10(1). https://doi.org/10.2202/1935-1682.2467.

Goldberg, P.K. (1998). “The Effects of the Corporate Average Fuel Economy Standards in the US.” The Journal of Industrial Economics 46: 1-33. https://doi.org/10.1111/1467-6451.00059.

Greaker, M. and K. Midttømme (2016). “Optimal Environmental Policy with Network Effects: Will Pigovian Taxation Lead to Excess Inertia?” Journal of Public Economics 143: 27-38. https://doi.org/10.1016/j.jpubeco.2016.08.004.

Grigolon, L., Mathias Reynart, and F. Verboven (2014). "Consumer valuation of fuel costs and the effectiveness of tax policy: Evidence from the European car market.” CEPR Discussion paper no. DP10301. https://doi.org/10.2139/ssrn.2533972.

Hammar, H., Å. Löfgren, and T. Sterner (2004). "Political Economy Obstacles to Fuel Taxation.” The Energy Journal 25(3): 1-17. https://doi.org/10.5547/ISSN0195-6574-EJ-Vol25-No3-1.

Hawkins, T.R., B. Sing, G. Majeau-Betterz, and A.H. Strømman (2012). Comparative Environmental Life Cycle Assessment of Conventional and Electric Vehicles Journal of Industrial Ecology 17(1).

Holtsmark, B. and A. Skonhoft (2014). "The Norwegian support and subsidy policy of electric cars. Should it be adopted by other countries?” Environmental Science and Policy 42. https://doi.org/10.1016/j.envsci.2014.06.006.

Innes, R. (1996). "Regulating Automobile Pollution under Certainty, Competition, and Imperfect Information." Journal of Environmental Economics and Management 31: 219-239. https://doi.org/10.1006/jeem.1996.0042.

IPCC (2007). Fourth Assessment report, Climate Change 2007: Working Group II: Impacts, Adaptation and Vulnerability.

Jacobs, Bas, and A. de Mooij Ruud (2015). "Pigou Meets Mirrlees: On the Irrelevance of Tax Distortions for the Second-Best Pigouvian Tax.” Journal of Environmental Economics and Management 71: 90-108. https://doi.org/10.1016/j. jeem.2015.01.003.

Jaeger, W.K. (2011). "The welfare effects of environmental taxation.” Environ. Resour. Econ. 49: 101-119. https://doi. $\operatorname{org} / 10.1007 / \mathrm{s} 10640-010-9426-\mathrm{x}$.

Jansen, H. and C. Denis (1999). “A welfare cost assessment of various policy measures to reduce pollutant emissions from passenger road vehicles." Transportation Research Part D: Transport and Environment 4(6): 379-396. https://doi. org/10.1016/S1361-9209(99)00017-6.

Klier, T. and J. Linn (2015). "Using Taxes to Reduce Carbon Dioxide Emissions Rates of New Passenger Vehicles: Evidence from France, Germany, and Sweden." American Economic Journal: Economic Policy 7(1): 212-242. https://doi. org/10.1257/pol.20120256.

Lin, C.-Y.C. and J. Zeng, J. (2014). “The Optimal Gasoline Tax for China.” Theoretical Economics Letters 4: $270-278$. https://doi.org/10.4236/tel.2014.44037.

Montag, J. (2015). "The simple economics of motor vehicle pollution: A case for fuel tax." Energy Policy 85: $138-149$. https://doi.org/10.1016/j.enpol.2015.05.020.

All rights reserved. Copyright (C) 2019 by the IAEE. 
Parry, I.W.H. (2002). "Comparing the efficiency of alternative policies for reducing traffic congestion." Journal of Public Economics 85: 333-362. https://doi.org/10.1016/S0047-2727(00)00163-8.

Parry, I.W.H. and K. A. Small (2005). "Does Britain or the United States Have the Right Gasoline Tax?" The American Economic Review 95(4). https://doi.org/10.1257/0002828054825510.

Parry, I.W.H., M. Walls, and W. Harrington (2007). “Automobile Externalities and Policies.” Journal of Economic Literature 45(2): 373-99. https://doi.org/10.1257/jel.45.2.373.

Sallee, J.M., S.E. West, and W. Fan (2016). "Do consumers recognize the value of fuel economy? Evidence from used car prices and gasoline price fluctuations." Journal of Public Economics 135: 61-73. https://doi.org/10.1016/j.jpubeco.2016.01.003.

Sandmo, A. (1976). "Direct versus indirect Pigovian taxation.” European Economic Review 7: 337-349. https://doi. org/10.1016/0014-2921(78)90010-7.

Shanjun, L., T. Lang, X. Juanwei, and Z. Yiyi (2017). "The market for Electric Vehicles: Indirect Network Effects and Policy Design." Journal of The Association of Environmental and Resource Economists 4(1).

Tscharaktschiew, S. (2015). "How much should gasoline be taxed when electric vehicles conquer the market? An analysis of the mismatch between efficient and existing gasoline taxes under emerging electric mobility." Transportation Research Part D 39: 89-113. https://doi.org/10.1016/j.trd.2015.06.007.

UK (2017). "Tax benefits for ultra-low emission vehicles.” https://www.gov.uk/government/uploads/system/uploads/attachment_data/file/519209/factsheet-tax-implications-refresh.pdf

\section{APPENDIX A}

First order equations w.r.t.

$$
\begin{aligned}
& t_{\text {car }}:-\frac{1}{a} u\left(d_{\text {high }}\left(t_{l}\right)\right)-\frac{1}{a} b_{\text {max }}+N+\frac{1}{a} u\left(d_{\text {low }}\left(t_{l}\right)\right)+\frac{1}{a}\left(p_{\text {car }, \text { high }}+p_{l} f_{\text {high }} d_{\text {high }}\left(t_{l}\right)\right) \\
& -\frac{1}{a}\left(p_{\text {car }, \text { low }}+p_{l} f_{\text {low }} d_{\text {low }}\left(t_{l}\right)\right)+\frac{1}{a} p_{\text {CO2 }} f_{\text {high }} d_{\text {high }}\left(t_{l}\right)-\frac{1}{a} p_{\text {CO2 }} f_{\text {low }} d_{\text {low }}\left(t_{l}\right)+\frac{1}{a} p_{d} d_{\text {high }}\left(t_{l}\right) \\
& -\frac{1}{a} p_{d} d_{\text {low }}\left(t_{l}\right)=0
\end{aligned}
$$

Note that $\frac{\partial N}{\partial t_{c a r}}=\frac{1}{-a}$ according to equation (7). If we multiply by $-a$, then

$$
\begin{aligned}
& u\left(d_{\text {high }}\left(t_{l}\right)\right)+b_{\text {max }}-a N-p_{\text {car }, \text { high }}-p_{l} f_{\text {high }} d_{\text {high }}\left(t_{l}\right)-p_{\text {CO2 }} f_{\text {high }} d_{\text {high }}\left(t_{l}\right)-p_{d} d_{\text {high }}\left(t_{l}\right) \\
& =u\left(d_{\text {low }}\left(t_{l}\right)\right)-p_{\text {car }, \text { low }}-p_{l} f_{\text {low }} d_{\text {low }}\left(t_{l}\right)-p_{\text {CO2 }} f_{\text {low }} d_{\text {low }}\left(t_{l}\right)-p_{d} d_{\text {low }}\left(t_{l}\right) .
\end{aligned}
$$

First order equations w.r.t. $t_{l}$ :

$$
\begin{aligned}
& \frac{f_{\text {low }} d_{\text {low }}\left(t_{l}\right)-f_{\text {high }} d_{\text {high }}\left(t_{l}\right)}{a}\left[u\left(d_{\text {high }}\left(t_{l}\right)\right)+b_{\text {max }}-a N(.)-u\left(d_{\text {low }}\left(t_{l}\right)\right)-p_{\text {car }, \text { high }}\right. \\
& -p_{l} f_{\text {high }} d_{\text {high }}\left(t_{l}\right)+p_{\text {car }, \text { low }}+p_{l} f_{\text {low }} d_{\text {low }}\left(t_{l}\right)-p_{\text {CO2 }} f_{\text {high }} d_{\text {high }}\left(t_{l}\right)+p_{\text {CO2 }} f_{\text {low }} d_{\text {low }}\left(t_{l}\right) \\
& \left.-p_{d} d_{\text {high }}\left(t_{l}\right)+p_{d} d_{\text {low }}\left(t_{l}\right)\right]+N(.) u_{\text {km }}^{\prime} d_{\text {high } t_{l}}^{\prime}-N(.) p_{l} f_{\text {high }} d_{\text {high } t_{l}}^{\prime} \\
& -N(.) p_{\text {CO2 }} f_{\text {high }} d_{\text {high } t_{l}}^{\prime}-N(.) p_{d} d_{\text {high } t_{l}}^{\prime}+(\bar{N}-N(.)) u_{\text {km }}^{\prime} d_{\text {low } t_{l}}^{\prime}-(\bar{N}-N(.)) p_{l} f_{\text {low }} d_{\text {low } t_{l}}^{\prime}
\end{aligned}
$$




$$
-(\bar{N}-N(.)) p_{\text {CO2 }} f_{\text {low }} d_{\text {low } t_{l}}^{\prime}-(\bar{N}-N(.)) p_{d} d_{\text {low } t_{l}}{ }^{\prime}=0 \text {. }
$$

Note that equation (7) implies that $\frac{\partial N}{\partial t_{l}}=\frac{f_{\text {low }} d_{\text {low }}\left(t_{l}\right)-f_{\text {high }} d_{\text {high }}\left(t_{l}\right)}{a}$. The first order equation w.r.t $t_{\text {car }}$ implies that the parameters in the first bracket equal zero. Hence, these conditions imply that

$$
\begin{aligned}
& \frac{N}{\bar{N}} \frac{d_{\text {high } t_{l}}^{\prime}}{d_{\text {low } t_{l}}^{\prime}} u^{\prime}\left(k m_{\text {high }}\right)+\frac{\bar{N}-N}{\bar{N}} u^{\prime}\left(k m_{\text {low }}\right)=\frac{N}{\bar{N}} \frac{d_{\text {high } t_{l}}^{\prime}}{d_{\text {low } t_{l}}^{\prime}} p_{l} f_{\text {high }}+\frac{\bar{N}-N}{\bar{N}} p_{l} f_{\text {low }} \\
& +\frac{N}{\bar{N}} \frac{d_{\text {high } t_{l}}^{\prime}}{d_{\text {low } t_{l}}^{\prime}} p_{C O 2} f_{\text {high }}+\frac{\bar{N}-N}{\bar{N}} p_{\text {CO2 }} f_{\text {low }}+\frac{N}{\bar{N}} \frac{d_{\text {high } t_{l}}^{\prime}}{d_{\text {low } t_{l}}^{\prime}} p_{d}+\frac{\bar{N}-N}{\bar{N}} p_{d}
\end{aligned}
$$

Multiplying equation (3) by $\frac{N}{\bar{N}}$ and $\frac{d_{\text {high } t_{l}}^{\prime}}{d_{\text {low } t_{l}}^{\prime}}$ gives

$$
\frac{N}{\bar{N}} \frac{d_{\text {high } t_{l}}{ }^{\prime}}{d_{\text {low } t_{l}}{ }^{\prime}} u^{\prime}\left(k m_{\text {high }}\right)=\frac{N}{\bar{N}} \frac{d_{\text {high } t_{l}}{ }^{\prime}}{d_{\text {low } t_{l}}{ }^{\prime}} p_{l} f_{\text {high }}+\frac{N}{\bar{N}} \frac{d_{\text {high } t_{l}}{ }_{d_{\text {low } t_{l}}{ }^{\prime}}^{\prime}}{t_{l}} f_{\text {high }}
$$

Multiplying equation (3) by $\frac{\bar{N}-N}{\bar{N}}$ gives

$$
\frac{\bar{N}-N}{\bar{N}} u^{\prime}\left(k m_{\text {low }}\right)=\frac{\bar{N}-N}{\bar{N}} p_{l} f_{\text {low }}+\frac{\bar{N}-N}{\bar{N}} t_{l} f_{\text {low }}
$$

Summing these equations:

$$
\begin{aligned}
& \frac{N}{\bar{N}} \frac{d_{\text {high } t_{l}}^{\prime}}{d_{\text {low } t_{l}}^{\prime}} u^{\prime}\left(k m_{\text {high }}\right)+\frac{\bar{N}-N}{\bar{N}} u^{\prime}\left(k m_{\text {low }}\right)=\frac{N}{\bar{N}} \frac{d_{\text {high } t_{l}}}{d_{\text {low } t_{l}}^{\prime}} p_{l} f_{\text {high }}+\frac{\bar{N}-N}{\bar{N}} p_{l} f_{\text {low }} \\
& +\frac{N}{\bar{N}} \frac{d_{\text {high } t_{l}}^{\prime}}{d_{\text {low } t_{l}}^{\prime}} t_{l} f_{\text {high }}+\frac{\bar{N}-N}{\bar{N}} t_{l} f_{\text {low }}
\end{aligned}
$$

The first order conditions w.r.t. $t_{l}$ and $t_{c a r}$, and this equation imply that

$$
\begin{aligned}
& \frac{N}{\bar{N}} \frac{d_{\text {high } t_{l}}^{\prime}}{d_{\text {low } t_{l}}^{\prime}} t_{l} f_{\text {high }}+\frac{\bar{N}-N}{\bar{N}} t_{l} f_{\text {low }}=\frac{N}{\bar{N}} \frac{d_{\text {high } t_{l}}^{\prime}}{d_{\text {low } t_{l}}^{\prime}} p_{\text {CO2 }} f_{\text {high }}+\frac{\bar{N}-N}{\bar{N}} p_{\text {CO2 }} f_{\text {low }} \\
& +\frac{N}{\bar{N}} \frac{d_{\text {high } t_{l}}^{\prime}}{d_{\text {low } t_{l}}^{\prime}} p_{d}+\frac{\bar{N}-N}{\bar{N}} p_{d}
\end{aligned}
$$

Hence, 


$$
t_{l}^{*}=p_{C O 2}+\frac{\left(N d_{{\text {high } t_{l}}^{\prime}}^{\prime}+(\bar{N}-N) d_{{\text {low } t_{l}}^{\prime}}^{\prime}\right) p_{d}}{N d_{\text {high } t_{l}}^{\prime} f_{\text {high }}+(\bar{N}-N) d_{\text {low } t_{l}}^{\prime} f_{\text {low }}}
$$

Substituting $t_{l}^{*}$ in equation (7) gives

$$
\begin{aligned}
& u\left(d_{\text {high }}\left(t_{l}^{*}\right)\right)+b_{\text {max }}-a N-p_{\text {car }, \text { high }}-t_{c a r}-p_{l} f_{\text {high }} d_{\text {high }}\left(t_{l}^{*}\right)
\end{aligned}
$$

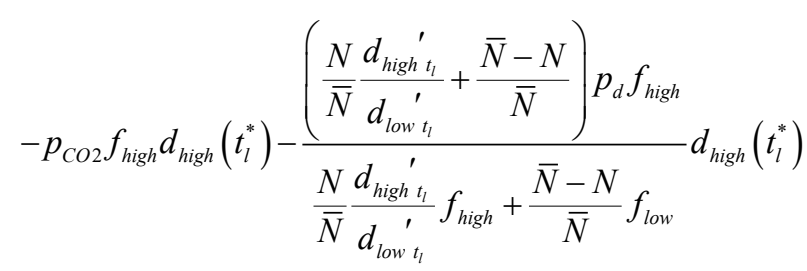

$$
\begin{aligned}
& =u\left(d_{\text {low }}\left(t_{l}^{*}\right)\right)-p_{\text {car }, \text { low }}-p_{l} f_{\text {low }} d_{\text {low }}\left(t_{l}^{*}\right)
\end{aligned}
$$

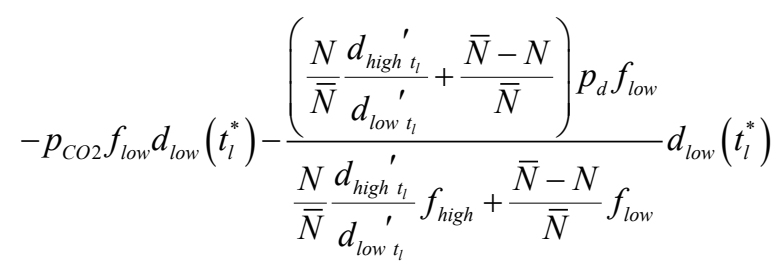

Hence,

$$
\begin{aligned}
& u\left(d_{\text {high }}\left(t_{l}^{*}\right)\right)+b_{\text {max }}-a N-p_{\text {car }, \text { high }}-t_{\text {car }}-p_{l} f_{\text {high }} d_{\text {high }}\left(t_{l}^{*}\right) \\
& -p_{\text {CO2 }} f_{\text {high }} d_{\text {high }}\left(t_{l}^{*}\right)-p_{d} d_{\text {high }}\left(t_{l}^{*}\right)-\frac{\left(\frac{\bar{N}-N}{\bar{N}}\right)\left[f_{\text {high }}-f_{\text {low }}\right]}{\frac{N}{\bar{N}} \frac{d_{\text {high } t_{l}}^{\prime}}{d_{\text {low } t_{l}}^{\prime}} f_{\text {high }}+\frac{\bar{N}-N}{\bar{N}} f_{\text {low }}} p_{d} d_{\text {high }}\left(t_{l}^{*}\right) \\
& =u\left(d_{\text {low }}\left(t_{l}^{*}\right)\right)-p_{\text {car }, \text { low }}-p_{l} f_{\text {low }} d_{\text {low }}\left(t_{l}^{*}\right)
\end{aligned}
$$

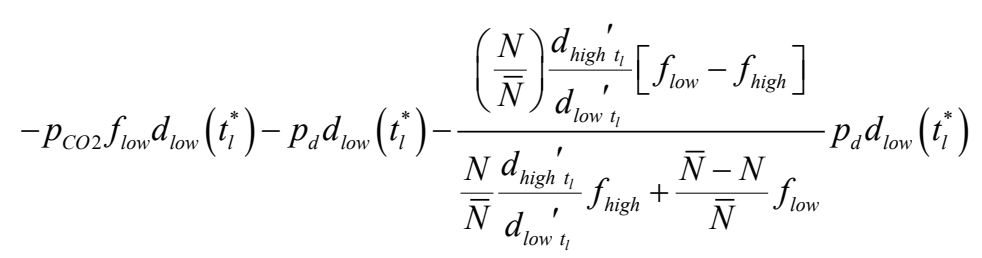

Implementing first order conditions v.r.t. $t_{c a r}$ gives 


$$
t_{\text {car }}^{*}=\frac{\frac{\bar{N}-N}{\bar{N}}\left(f_{\text {low }}-f_{\text {high }}\right)}{\frac{N}{\bar{N}} \frac{d_{\text {high } t_{l}}^{\prime}}{d_{\text {low } t_{l}}^{\prime}} f_{\text {high }}+\frac{\bar{N}-N}{\bar{N}} f_{\text {low }}} p_{d} d_{\text {high }}\left(t_{l}^{*}\right)+\frac{\frac{N}{\bar{N}} \frac{d_{\text {high } t_{l}}^{\prime}}{d_{\text {low } t_{l}}^{\prime}}\left(f_{\text {low }}-f_{\text {high }}\right)}{\frac{N}{\bar{N}} \frac{d_{\text {high } t_{l}}^{\prime}}{d_{\text {low } t_{l}}^{\prime}} f_{\text {high }}+\frac{\bar{N}-N}{\bar{N}} f_{\text {low }}} p_{d} d_{\text {low }}\left(t_{l}^{*}\right)
$$

Both expressions on the right-hand side are negative. This proves that $t_{c a r}^{*}$ is negative.

\section{APPENDIX B}

Second order conditions for the government maximization problem, equation (13). The welfare function is labeled $\mathrm{W}$.

$$
\begin{aligned}
& \frac{\partial^{2} W}{\partial t_{l} \partial t_{l}}=\frac{f_{\text {low }} d_{\text {low }}\left(t_{l}\right)-f_{\text {high }} d_{\text {high }}\left(t_{l}\right)}{a}\left[-a\left[\frac{f_{\text {low }} d_{\text {low }}\left(t_{l}\right)-f_{\text {high }} d_{\text {high }}\left(t_{l}\right)}{a}\right]\right. \\
& +u_{\text {km }}^{\prime} d_{\text {high } t_{l}}^{\prime}-p_{l} f_{\text {high }} d_{\text {high } t_{l}}^{\prime}-p_{\mathrm{CO} 2} f_{\text {high }} d_{\text {high } t_{l}}^{\prime}-p_{d} d_{\text {high } t_{l}}^{\prime} \\
& \left.-u_{\text {km }}^{\prime} d_{\text {low } t_{l}}^{\prime}+p_{l} f_{\text {low }} d_{\text {low } t_{l}}^{\prime}+p_{\text {CO2 } 2} f_{\text {low }} d_{\text {low } t_{l}}^{\prime}+p_{d} d_{\text {low } t_{l}}^{\prime}\right] \\
& +\frac{f_{\text {low }} d_{\text {low }}\left(t_{l}\right)-f_{\text {high }} d_{\text {high }}\left(t_{l}\right)}{a}\left[u_{\text {km }}^{\prime} d_{\text {high } t_{l}}^{\prime}-p_{l} f_{\text {high }} d_{\text {high } t_{l}}^{\prime}-p_{\text {CO2 } 2} f_{\text {high }} d_{\text {high } t_{l}}^{\prime} .\right. \\
& \left.-p_{d} d_{\text {high } t_{l}}^{\prime}-u_{\text {km }}^{\prime} d_{\text {low } t_{l}}^{\prime}+p_{l} f_{\text {low }} d_{\text {low } t_{l}}^{\prime}+p_{\text {CO2 }} f_{\text {low }} d_{\text {low } t_{l}}^{\prime}+p_{d} d_{\text {low } t_{l}}^{\prime}\right] \\
& +N\left(t_{l}, t_{\text {car }}\right)\left[u^{\prime} \underset{k m k m}{\prime} d_{\text {high } t_{l}}^{\prime} d_{\text {high } t_{l}}^{\prime}+u_{\text {km }}^{\prime} d_{\text {high } t_{l} t_{l}}^{\prime}-p_{l} f_{\text {high }} d_{\text {high } t_{l} t_{l}}^{\prime}-p_{\mathrm{CO} 2} f_{\text {high }} d_{\text {high } t_{l} t_{l}}^{\prime}\right. \\
& -p_{d} d_{\text {high } t_{l} t_{l}}^{\prime}-u_{\text {km km }}^{\prime} d_{\text {low } t_{l}}^{\prime} d_{\text {low } t_{l}}^{\prime}-u_{\text {km }}^{\prime} d_{\text {low } t_{l} t_{l}}^{\prime}+p_{l} f_{\text {low }} d_{\text {low } t_{l} t_{l}}^{\prime}+p_{\text {CO2 }}^{\prime} f_{\text {low }}^{\prime} d_{\text {low } t_{l} t_{l}}^{\prime \prime} \\
& \left.+p_{d} d_{\text {low } t_{l} t_{l}}^{\prime}\right]+\bar{N}\left[u_{\text {km km }}^{\prime}{ }^{\prime} d_{\text {low } t_{l}}^{\prime} d_{\text {low } t_{l}}^{\prime}+u_{\text {km }}^{\prime} d_{\text {low } t_{l} t_{l}}^{\prime}-p_{l} f_{\text {low }}^{\prime} d_{\text {low } t_{l} t_{l}}^{\prime}-p_{\text {CO2 } 2}^{\prime} f_{\text {low }} d_{\text {low } t_{l} t_{l}}^{\prime}\right. \\
& \left.-p_{d} d_{\text {low } t_{l} t_{l}}^{\prime},{ }^{\prime}\right]<0 \\
& \frac{\partial^{2} W}{\partial t_{c a r} \partial t_{c a r}}=\frac{1}{-a}<0 \\
& \frac{\partial^{2} W}{\partial t_{l} \partial t_{\text {car }}}=\frac{f_{\text {low }} d_{\text {low }}\left(t_{l}\right)-f_{\text {high }} d_{\text {high }}\left(t_{l}\right)}{a}-\frac{1}{a}\left[u_{\text {km }}^{\prime} d_{\text {high } t_{l}}^{\prime}-p_{l} f_{\text {high }} d_{\text {high } t_{l}}^{\prime}-p_{\text {CO2 }} f_{\text {high }} d_{\text {high } t_{l}}^{\prime}\right. \\
& \left.-p_{d} d_{\text {high } t_{l}}{ }^{\prime}-u_{\text {km }}^{\prime} d_{\text {low } t_{l}}^{\prime}+p_{l} f_{\text {low }} d_{\text {low } t_{l}}^{\prime}+p_{\text {CO2 }} f_{\text {low }} d_{\text {low } t_{l}}{ }^{\prime}+p_{d} d_{\text {low } t_{l}}{ }^{\prime}\right]
\end{aligned}
$$


The second order condition is satisfied if

$$
\frac{\partial^{2} W}{\partial t_{c a r} \partial t_{c a r}}<0 \text { and } \frac{\partial^{2} W}{\partial t_{c a r} \partial t_{c a r}} \frac{\partial^{2} W}{\partial t_{l} \partial t_{l}}-\left(\frac{\partial^{2} W}{\partial t_{l} \partial t_{c a r}}\right)^{2}>0
$$

The first inequality condition is satisfied if $a>0$.

The second inequality condition is satisfied when

$$
\begin{aligned}
& -\frac{1}{a} N\left(t_{l}, t_{\text {car }}\right)\left[u_{\text {km km }}^{\prime} d_{\text {high } t_{l}}^{\prime} d_{\text {high } t_{l}}^{\prime}+u_{\text {km }}^{\prime} d_{\text {high } t_{l} t_{l}}^{\prime}-p_{l} f_{\text {high }} d_{\text {high } t_{l} t_{l}}^{\prime}-p_{\mathrm{CO} 2} f_{\text {high }} d_{\text {high } t_{l} t_{l}}^{\prime}\right. \\
& -p_{d} d_{\text {high } t_{l} t_{l}}^{\prime \prime}-u_{\text {km km }}^{\prime}{ }_{\text {low } t_{l}}^{\prime} d_{\text {low } t_{l}}^{\prime}-u_{k m}^{\prime} d_{\text {low } t_{l} t_{l}}^{\prime}+p_{l} f_{\text {low }} d_{\text {low } t_{l} t_{l}}^{\prime \prime} \\
& \left.+p_{\mathrm{CO} 2} f_{\text {low }} d_{\text {low } t_{l} t_{l}}^{\prime}+p_{d} d_{\text {low } t_{l} t_{l}}^{\prime}\right]-\frac{1}{a^{2}}\left[u_{\text {km }}^{\prime} d_{\text {high } t_{l}}^{\prime}-p_{l} f_{\text {high }} d_{\text {high } t_{l}}^{\prime}-p_{\mathrm{CO} 2}^{\prime} f_{\text {high }} d_{\text {high } t_{l}}^{\prime}\right. \\
& \left.-p_{d} d_{\text {high } t_{l}}{ }^{\prime}-u_{\text {km }}^{\prime} d_{\text {low } t_{l}}{ }^{\prime}+p_{l} f_{\text {low }} d_{\text {low } t_{l}}{ }^{\prime}+p_{\text {CO2 } 2} f_{\text {low }} d_{\text {low } t_{l}}{ }^{\prime}+p_{d} d_{\text {low } t_{l}}{ }^{\prime}\right]^{2}>0
\end{aligned}
$$

Parameter values and functional forms are restricted to those that satisfy this condition. These restrictions are also sufficient to satisfy the second order conditions in the case with myopic behavior.

\section{APPENDIX C}

Second order conditions for the government maximization problem, equation (19).

$$
\begin{aligned}
& N\left(t_{l}, t_{\text {car }}\right)\left[u^{\prime}{ }_{\text {km km }}^{\prime}{ }_{\text {high } t_{l}}^{\prime} d_{\text {high } t_{l}}^{\prime}+u_{\text {km }}^{\prime} d_{\text {high } t_{l} t_{l}}^{\prime}-p_{l} f_{\text {high }} d_{\text {high } t_{l} t_{l}}^{\prime}-p_{\mathrm{CO} 2} f_{\text {high }} d_{\text {high } t_{l} t_{l}}^{\prime}\right. \\
& \left.-p_{d} d_{\text {high } t_{l} t_{l}}^{\prime}\right]+(\bar{N}-N)\left[u_{\text {km km }}^{\prime}{ }_{\text {low } t_{l}}^{\prime} d_{\text {low } t_{l}}^{\prime}+u_{k m}^{\prime} d_{\text {low } t_{l} t_{l}}^{\prime}-p_{l}^{\prime} f_{\text {low }}^{\prime} d_{\text {low } t_{l} t_{l}}^{\prime}\right. \\
& \left.-p_{\mathrm{CO} 2} f_{\text {low }} d_{\text {low } t_{l} t_{l}}^{\prime},-p_{d} d_{\text {low } t_{l} t_{l}}^{\prime}\right]<0
\end{aligned}
$$

Parameter values and functional forms are restricted to those that satisfy this condition.

\section{APPENDIX D}

Equation (20) is modified so that

$$
\begin{aligned}
& \frac{0,3}{0,7}\left[b_{\text {max }}-a N\left(t_{l}^{* * *}, t_{\text {car }}\right)-p_{\text {car }, \text { high }}-t_{\text {car }}-p_{\text {car }, \text { low }}\right] \\
& +u\left(d_{\text {high }}\left(t_{l}^{* * *}\right)\right)+b_{\text {max }}-a N\left(t_{l}^{* * *}, t_{\text {car }}\right)-p_{\text {car }, \text { high }}-t_{\text {car }}-\left(p_{l}+t_{l}^{* * *}\right) f_{\text {high }} d_{\text {high }}\left(t_{l}^{* * * *}\right) \\
& =u\left(d_{\text {low }}\left(t_{l}^{* * * *}\right)\right)-p_{\text {car }, \text { low }}-\left(p_{l}+t_{l}^{* * *}\right) f_{\text {low }} d_{\text {low }}\left(t_{l}^{* * *}\right)
\end{aligned}
$$


The only difference between this condition and equation (7) is the first term on the left-hand side. Hence, implementing equations (21) and (14) implies that

$$
\begin{aligned}
& t_{\text {car }}^{* * *}=\frac{\frac{\bar{N}-N}{\bar{N}}\left(f_{\text {low }}-f_{\text {high }}\right)}{\frac{N}{\bar{N}} \frac{d_{\text {high } t_{l}}^{\prime}}{d_{\text {low } t_{l}}^{\prime}} f_{\text {high }}+\frac{\bar{N}-N}{\bar{N}} f_{\text {low }}} p_{d} d_{\text {high }}\left(t_{l}^{* * *}\right)+\frac{\frac{N}{\bar{N}} \frac{d_{\text {high } t_{l}}^{\prime}}{d_{\text {low } t_{l}}^{\prime}}\left(f_{\text {low }}-f_{\text {high }}\right)}{\frac{N}{\bar{N}} \frac{d_{\text {high } t_{l}}^{\prime}}{d_{\text {low } t_{l}}^{\prime}} f_{\text {high }}+\frac{\bar{N}-N}{\bar{N}} f_{\text {low }}} p_{d} d_{\text {low }}\left(t_{l}^{* * *}\right) \\
& +\frac{0,3}{0,7}\left[b_{\text {max }}-a N\left(t_{l}^{* * *}, t_{\text {car }}^{* * *}\right)-p_{\text {car }, \text { high }}-t_{\text {car }}^{* * *}-p_{\text {car }, \text { low }}\right]
\end{aligned}
$$

Implementing equation (21) implies that

$$
\begin{aligned}
& t_{\text {car }}^{* * *}=\frac{\frac{\bar{N}-N}{\bar{N}}\left(f_{\text {low }}-f_{\text {high }}\right)}{\frac{N}{\bar{N}} \frac{d_{\text {high } t_{l}}^{\prime}}{d_{\text {low } t_{l}}^{\prime}} f_{\text {high }}+\frac{\bar{N}-N}{\bar{N}} f_{\text {low }}} p_{d} d_{\text {high }}\left(t_{l}^{* * *}\right)+\frac{\frac{N}{\bar{N}} \frac{d_{\text {high } t_{l}}^{\prime}}{d_{\text {low } t_{l}}^{\prime}}\left(f_{\text {low }}-f_{\text {high }}\right)}{\frac{N}{\bar{N}} \frac{d_{\text {high } t_{l}}^{\prime}}{d_{\text {low } t_{l}}^{\prime}} f_{\text {high }}+\frac{\bar{N}-N}{\bar{N}} f_{\text {low }}} p_{d} d_{\text {low }}\left(t_{l}^{* * * *}\right) \\
& +0,3\left[u\left(d_{\text {low }}\left(t_{l}^{* * *}\right)\right)-\left(p_{l}+t_{l}^{* * *}\right) f_{\text {low }} d_{\text {low }}\left(t_{l}^{* * *}\right)-\left(u\left(d_{\text {high }}\left(t_{l}^{* * *}\right)\right)-\left(p_{l}+t_{l}^{* * *}\right) f_{\text {high }} d_{\text {high }}\left(t_{l}^{* * *}\right)\right)\right]
\end{aligned}
$$

\section{APPENDIX E}

A linear approximation of the accumulated demand for driving distance minus total private fuel costs for fuel-efficient vehicles equals the area abc in Figure 3. Accumulated demand for driving distance minus total private fuel costs for fuel-intensive vehicles equals the area cde. Hence, the difference between the accumulated demand for driving distance minus total private fuel costs for fuel-intensive and fuel-efficient vehicles equals the area abde. When estimates of current prices and taxes measured in dollars, driving and fuel consumption, $p_{l}=0,5, p_{\mathrm{CO} 2}=0,116, \frac{p_{d}}{\bar{f}}=0,507$, $t_{l}^{*}=0,623, \bar{f}=0,5 f_{\text {low }}+0,5 f_{\text {high }}, f_{\text {high }}=0,051, f_{\text {low }}=0,041, \mathrm{~km}_{\text {high }}=240.000, \mathrm{~km}_{\text {low }}=250.000$, are applied, the area abde is found to equal $\$ 2,751.35$. Thirty percent of abde amounts to approximately $\$ 825$.

\section{Figure 3.}

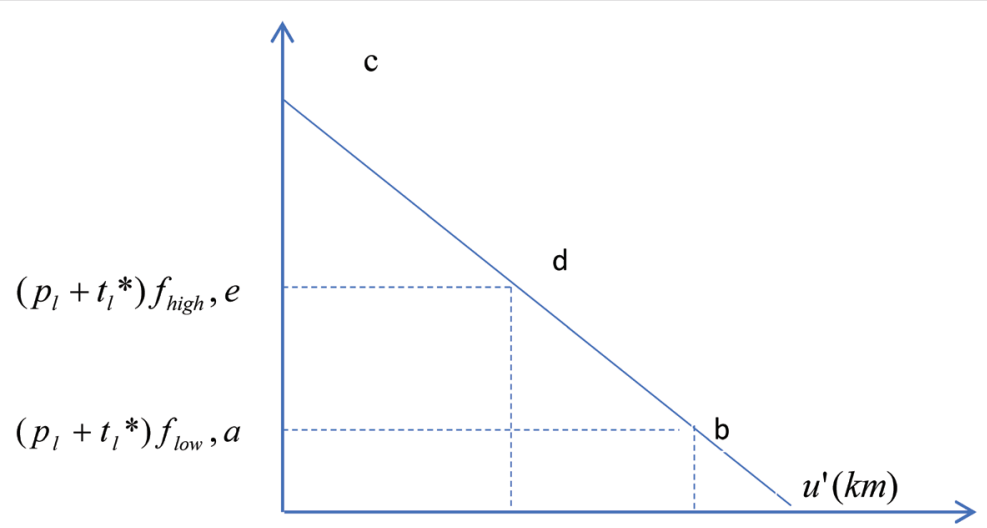

